\title{
Seeking Quality Mentors: Exploring Program Design to Increase Mentor Participation
}

\author{
Kristen R. Voetmann \\ Seattle Pacific University \\ Dana L. Kendall \\ Seattle Pacific University
}

The purpose of this study is to explore the causal relationship between mentoring program design and mentor participation. Results indicated that offering time in work significantly increased a mentor's willingness to participate and a mediation analysis revealed that time in work increased an individual's likelihood to participate through the mechanism of perceived organizational support.

Keywords: Mentor, Formal Mentoring, Organizational Support, Mentor Personality, Mentoring, Mentoring Program Design

\section{INTRODUCTION}

As the impact of generational differences begins to affect organizations, there is an increased need to create ways of passing on organizational knowledge before older generations, who tend to exhibit greater organizational commitment, leave the workforce and to increase retention of younger employees to reduce the high cost of turnover (Costanza, Badger, Fraser, Severt, \& Gade, 2012; Lyons, Ng, \& Schweitzer, 2014). Previously, one way these efforts occurred naturally was through organically-formed mentoring relationships, which have demonstrated positive outcomes for the protégé's career commitment and development (Allen, Eby, Poteet, Lentz, \& Lima, 2004; Castro, Scandura, \& Williams, 2004; Dreher $\&$ Ash, 1990). Informal mentoring relationships, however, are not guaranteed to form in every organization. Formal mentoring programs have been recognized as a best practice for organizations (Allen, Finkelstein, \& Poteet, 2009; Branch, 1999). In the current study, we examined the causal relationship between formal mentoring program design and a potential, quality mentor's likelihood to participate. To more thoroughly understand the process of the causal relationship, we explored the potential mediating effect of organizational support. The results of the current study will help organizations prioritize resources to design programs with the greatest opportunity of recruiting quality mentors.

\section{Potential Barrier to Mentor Participation}

One of the reasons it is imperative to consider the mentor's perspective is the considerable amount of time and energy they may invest in the mentoring relationship. Research suggests that an individual is 
more likely to mentor if they have previously engaged in a mentoring relationship (Bozionelos, 2004; Ragins \& Cotton, 1993; Ragins \& Scandura, 1999). However, an organization cannot simply hope that there exists a plethora of experienced individuals in their organization, who have had previous mentoring experience, intend to mentor others, and will initiate a mentoring relationship. The organization is thus tasked with taking a proactive role to increase a potential mentor's likelihood to participate (Ragins \& Scandura, 1999).

Although it is recognized that individuals who have a prosocial orientation (Allen, 2003) and those who rank high on openness to experience (Bozionelos, 2004) are more likely to mentor, they may yet choose not to participate due to the personal and professional resources required to be an effective mentor. Additionally, as the current pace of work continues to accelerate and increasing responsibilities are placed on more experienced individuals, the prospect of their electing to serve as mentors may be decreased (Allen, Poteet, \& Burroughs, 1997). Potential mentors, who may have the requisite skills and personality to be effective mentors, are often the same individuals who already have competing demands on their time (Allen et al., 2009), which may decrease their choice to participate if the role is perceived as an additional task in an already busy schedule. When adequate time to facilitate a mentoring relationship at work is not provided, it is perceived as a major cost to participation and diminishes the likelihood that a qualified mentor might participate (Ragins \& Scandura, 1999).

\section{Program Design to Overcome a Potential Barrier}

In preparation for this investigation, we conducted a non-experimental pre-study replicating Ragins and Scandura's (1999) exploration of the costs and benefits of mentoring to ascertain which program design would be most attractive to a potential mentor. Results corroborated prior research indicating that time in work would most likely correlate with a potential, quality mentor's likelihood to participate.

A practical step to help mitigate the negative effects of busy schedules becoming overloaded with extra-role opportunities leading to exhaustion of high-quality employees is to provide time in work to facilitate the mentoring relationship. Grant (2008) suggests that it is important to design jobs in such a way as to enable individuals to do good and to do well. In this way, an organization could be perceived as providing support for its employees by offering space in the workday to glean the benefits of a mentoring relationship rather than attempting to squeeze in an additional role.

Hypothesis 1: Programs that offer time in work to facilitate a mentoring relationship will result in higher likelihood to participate as a mentor in a formal mentoring program than programs that do not offer time in work.

\section{Perceived Organizational Support as a Mediator}

Perceived Organizational Support (POS) stems from the larger body of work encompassing Organizational Support Theory, which posits that employees' perceptions of an organization are largely based upon the extent to which the organization values employee well-being and contribution (Kurteiss, Eisenberger, Ford, Buffardi, Steward, \& Adis, 2015). Increasing employee POS is a benefit, in and of itself, to the organization as it may be more likely to retain high-quality employees and reduce the associated turnover costs (Dawley, Andrews, \& Buckley, 2007; 2010). One avenue that may effectively stimulate POS is for an organization to provide opportunities for mentoring, which has similarly been demonstrated to reduce employee turnover intentions (Dawley et al., 2007; 2010) and provide affective care through psychosocial support (Kram, 1985; Ragins \& Kram, 2007). In the current study, we seek to understand how formal mentoring program design positively impact a potential mentor's likelihood to participate as a mentor in a formal program. This relationship is hypothesized to occur through increasing employees' POS.

Hypothesis 2: Formal mentoring programs that offer time in work to facilitate a mentoring relationship will positively impact a potential mentors' likelihood to participate through increased perceptions of organizational support. 
The focus of the current study is to provide evidence-based research regarding how program design will most likely increase a potential mentor's choice to participate. The results are intended to provide practical methods by which organizations can justify the prioritization of resources when designing a successful formal mentoring program.

\section{METHOD}

\section{Participants and Sampling}

There were five inclusion criteria that participants had to fulfill to participate. Participants had to 18 years of age or older, reside in the United States, employed at least part-time outside of the home at least three days a week, and have a minimum of five years' work experience. Data was collected through Amazon's Mechanical Turk (MTurk), which is an online marketplace where people may take surveys or complete projects if they meet the requirements (Buhrmester, Kwang, \& Gosling, 2011). Data collected via MTurk has been demonstrated to be comparable to data collected via a traditional laboratory study and may perhaps be a better tool due to its anonymity (Berinsky, Huber, \& Lenz, 2012; Shapiro, Chandler, \& Mueller, 2013).

\section{Sampling and Power}

If MTurk participants met the requirements, they were directed to Qualtrics to take the survey. There were three data checks built in to ensure quality data and reduce careless responding. Each of the scenarios needed to have a minimum of 64 participants to detect a medium effect size, with a power set at a minimum of .80, and alpha set at .05 (Cohen, 1992). An a priori power analysis revealed that for a mediation analysis using a bias-corrected bootstrap method, the sample should include at least 71 participants to detect a medium effect size on both the $a$ and $b$ paths with power set to $80 \%$ (Fritz \& MacKinnon, 2007). After eliminating cases due to missingness and careless responding, a total sample of 288 participants was retained for the study, well exceeding the recommended sample size.

\section{Manipulations and Measures}

To provide a consistent conceptualization of a formal mentoring program, the following description was included in the survey: "For the purpose of this entire survey, a formal program is defined as a mentoring program that is sponsored by an organization."

\section{Program Design}

Two scenarios were created inviting a potential mentor to participate in a formal mentoring program. One did not provide a form of organizational support while the other offered time in work. A manipulation check was included to ensure that participants clearly differentiated the scenarios.

\section{Likelihood to Participate as a Mentor}

Ragins and Scandura (1999) adapted Ragins and Cotton's (1993) intention to mentor scale by including the original two items: "I would like to be a mentor" and "I have no desire to be a mentor" and adding two items: "I intend to be a mentor" and "I would be comfortable assuming a mentoring role." Each of the four items was assessed on a 7-point Likert scale ranging from 1 (strongly disagree) to 7 (strongly agree). In the current study, $\alpha=.91$.

\section{Perceived Organizational Support}

Eisenberger, Huntington, Hutchison, and Sowa (1986) originally developed a 36-item measure for POS. In attempt to create a shorter version, multiple iterations were examined resulting in the current sixitem measure (Bear \& Hwang, 2015; Eisenberger, Armeli, Rexwinkel, Lynch, \& Rhoades, 2001; Shanock \& Eisenberger, 2006). An example item is: "The organization really cares about my well-being."

Participants were asked to rate their responses to the statements about their organization on a 7-point Likert scale ranging from 1 (strongly disagree) to 7 (strongly agree). $\alpha=.83$ in the current study. 


\section{Prosocialness Scale for Adults}

Caprara, Steca, Zelli, and Capanna (2005) introduced the prosocialness scale for adults. The scale comprises 16-items measured on a 5-point Likert scale ranging from 1 (never/almost never true) to 5 (almost always/always true) that can be aggregated for a single score. An example item is: "I try to help others." In the current study, $\alpha=.94$.

\section{Big Five Mini-Markers Adjective Check List}

Saucier (1994) refined the FFM adjective list developed by Goldberg (1990). Participants were asked to rate themselves on 40-adjectives using a 9-point Likert ranging from 1 (extremely inaccurate) to 9 (extremely accurate). In the current study, $\alpha=.77$.

\section{RESULTS}

\section{Data Preparation and Preliminary Analyses}

Originally, 461 participants were collected via MTurk. Through the data cleaning process, the final sample included 288 participants distributed fairly evenly across the scenarios. The final sample was predominantly white (71\%), reported an average age of 35 years, and an average of 13 years of work experience. There was a nearly equal representation of males and females (54\% and $46 \%$ respectively) across a variety of industries (i.e., no single industry represented more than $15 \%$ of the total sample). A missing analysis was conducted at the item-level revealing no missingness above $5 \%$ for all except for six cases. For each scale, the items were aggregated by computing the mean and calculated only if $75 \%$ of data were present for each scale. Table 1 displays descriptives and bivariate correlations among study variables.

\section{Primary Analyses}

In Hypothesis 1, we proposed that a formal mentoring program that offered its participants time in work to facilitate a mentoring relationship would result in a higher likelihood that an individual would participate as a mentor compared to a program that did not provide a form of organizational support. Results indicated a significant difference between the program design without any form of organizational support $(M=5.15, S D=1.42)$ and the program design that provided time in work $(M=5.74, S D=1.06)$.

In Hypothesis 2, we proposed that the positive relationship between program design and likelihood to participate as a mentor is facilitated through the mediating mechanism of increased organizational support. Results of the mediation analysis for Hypothesis 2 (See Table 2) indicated that there is a significant indirect effect of the program design offering time in work to facilitate a mentoring relationship on an individual's likelihood to participate as a mentor through POS $\left(B_{\mathrm{ab}}=.33 ; \mathrm{BC} 95 \% \mathrm{CI}=\right.$ .13 to .52$)$.

\section{DISCUSSION}

Overall, the results of the current study suggest that when designing a formal mentoring program with the greatest likelihood of recruiting potential, quality mentors, it is more effective to provide time in work. Based on the results of the current study, there are practical implications to address as well as limitations and future research to consider.

\section{Implications for Practice}

As organizations continue to explore formal mentoring programs as means to recruit new employees (Allen \& O'Brien, 2006; Horvath, Wasko, \& Bradley, 2008) and to glean the career benefits that often stem from organically-formed mentoring relationships (Allen et al., 2004; Castro, et al., 2004; Dreher \& Ash, 1990), there are two implications based on the current study to consider when designing a formal mentoring program. 


\section{Fostering Mentoring Relationships during the Workday}

As one of the most consistent issues reported within a formal mentoring program has been the participants' lack of time to facilitate a mentoring relationship (Kashiwagi, Varkey, \& Cook, 2013; Stenfors-Hayes et al., 2010), it is not surprising in the current study that the program design that offered time in work related positively to an individual's likelihood to participate as mentor. This suggests that an effective method to recruit quality mentors is to provide space within a busy workday to partake in a mentoring relationship. Given the high-pressure environments within organizations and the felt-need to "do" and "be" everything as an employee (Reid \& Ramarajan, 2016), one of the challenges that organizations may encounter is how to practically provide the necessary time. Within companies, for example, there may be various community tasks in which employees engage periodically (e.g., cleaning a shared kitchen space). If an employee opts to serve as a mentor, the organization could offer dispensation from these communal tasks given that the mentor is providing other services that benefit the greater community.

Another example to provide time in work is to utilize the lunch hour for mentoring meetings. One Midwestern consumer goods organization provides a lunch-ticket program that offers meal tickets for the mentor and protégé so that they have time to meet during the workday (Matarazzo \& Finkelstein, 2015). Recognizably, this also requires some measure of financial investment on behalf of the organization. Perhaps offering coffee cards would be a more cost-effective approach. If monetary support is not feasible for an organization, the mentoring dyad could be allowed to leave work an hour early if they use their personal lunch hours for the mentoring meeting. Finally, an organization could provide short-term coverage of a mentor's tasks to provide the time necessary to facilitate a mentoring relationship. One way this has been implemented in a Northwest school district was to create a mentoring program that recruited high-performing teachers to serve as mentors for lower-performing teachers by providing coverage of their classes during required mentoring responsibilities. The school district provided a substitute when the mentoring teacher attended the initial training workshop and when subsequent visits were made to the protégé's class to observe and provide feedback. It is important that there should be very clear expectations outlined regarding how time is offered to prevent individuals from taking advantage of the program.

\section{Organization Support}

Based on the mediation analyses, results suggest that time in work was regarded by the participants as a form of organizational support. This, in turn, led to a positive relationship with a potential mentor's likelihood to participate. Some organizations design formal mentoring programs that provide incentives for mentoring such as monetary compensation for the time mentors invest (Dickerson et al., 2016; Newby $\&$ Heide, 1992). The challenge would be to find an appropriate amount that would incentivize those who would be quality mentors rather than encourage participants simply based on the financial benefit. Ultimately, the impact of support should be underscored as a vital method to encourage opportunities to improve affective commitment to the organization and to enhance employee performance (Eisenberger et al., 1986; Rhoades \& Eisenberger, 2002). Further research is needed to better understand what other forms of organizational support would also positively impact a potential, quality mentor's likelihood to participate. Future research should examine other forms of organizational support that would motivate employees to participate in a formal mentoring program.

\section{Limitations and Future Directions}

The central limitation of the current study is the potential for reduced external validity due to the use of vignettes to invite participants to serve as a mentor. Although vignettes have been demonstrated to be a more effective tool than abstract questions because they provide greater context (Aguinis \& Bradley, 2014; Alexander \& Becker, 1978), the challenge is that they are not fully reflective of real-life situations given the lack of actual consequence of participants' decisions within a research study (Lohrke, Holloway, \& Woolley, 2010). Realistically, the choice to participate as a mentor may require additional consideration before an individual agrees to commit to invest in an actual mentoring relationship. Without 
the actual responsibility, participants may have been more likely to express a positive inclination to participate as a mentor given that they did not actually have to forfeit their personal time and energy.

The current study also provides a platform from which to examine an additional area of future research. One element of a formal mentoring program that was not included in the current study that may influence an individual's choice to serve as a mentor is whether participation is voluntary. When individuals willingly choose to serve as a mentor, they tend to perceive it as a rewarding experience (Parise \& Forret, 2008). One reason this may be valuable is that it mirrors the process of electing to participate as a mentor in an informal relationship. This might suggest that an important aspect of designing a formal mentoring program with the greatest likelihood of recruiting quality mentors is to ensure that participation is voluntary instead of being mandated. However, if the program is required then the results of the current study would suggest that the program should be designed to provide time in work to facilitate the mentoring relationship.

\section{CONCLUSION}

Results of the current study contribute to the mentoring literature by providing empirical evidence about how to design formal mentoring programs. Specifically, we examined how program design led to a quality mentor's likelihood to participate as a mentor. When recruiting individuals to serve as mentors in formal mentoring programs, one viable way to increase their likelihood to participate is to provide time in work for them to facilitate a mentoring relationship. The intention of the current study is to contribute to the growing literature on formal mentoring programs and to provide practical methods for organizations to use when creating opportunities for employee growth and development.

\section{REFERENCES}

Aguinis, H., \& Bradley, K. J. (2014). Best practice recommendations for designing and implementing experimental vignette methodology studies. Organizational Research Methods, 17, 351-371. doi:10.1177/1094428114547952

Alexander, C., \& Becker, H. (1978). The use of vignettes in survey research. Public Opinion Quarterly, 42, 93-104.

Allen, T. D. (2003). Mentoring others: A dispositional and motivational approach. Journal of Vocational Behavior, 62, 134-154. doi:10.1016/S0001-8791(02)00046-5

Allen, T. D., Eby, L. T., Poteet, M. L., Lentz, E., \& Lima, L. (2004). Career benefits associated with mentoring for protégés: A meta-analysis. Journal of Applied Psychology, 89, 127-136. doi:10.1037/0021-9010.89.1.127

Allen, T. D., Finkelstein, L. M., \& Poteet, M. L. (2009). Designing workplace mentoring programs: An evidence-based approach. Malden, MA: Wiley-Blackwell.

Allen, T. D., \& O'Brien, K. E. (2006). Formal mentoring programs and organizational attraction. Human Resource Development Quarterly, 17, 43-58. doi:10.1002/hrdq.1160

Allen, T. D., Poteet, M. L., \& Burroughs, S. M. (1997). The mentor's perspective: A qualitative inquiry and future research agenda. Journal of Vocational Behavior, 51, 70-89. doi:10.1006/jvbe.1997.1596

Berinsky, A. J., Huber, G. A., \& Lenz, G. S. (2012). Evaluating online labor markets for experimental research: Amazon.com's Mechanical Turk. Political Analysis, 20, 351-368.

Bozionelos, N. (2004). Mentoring provided: Relation to mentor's career success, personality, and mentoring received. Journal of Vocational Behavior, 64, 24-46. doi:10.1016/S00018791(03)00033-2

Branch, S. (1999, January 11). The 100 best companies to work for in America. Fortune, 139, 118-130.

Buhrmester, M., Kwang, T., \& Gosling, S. D. (2011). Amazon's Mechanical Turk: A new source of inexpensive, yet high-quality, data? Perspectives on Psychological Science, 6, 3-5. 
Caprara, G. V., Steca, P., Zelli, A., \& Capanna, C. (2005). A new scale for measuring adults' prosocialness. European Journal of Psychological Assessment, 21(2), 77-89. doi:10.1027/10155759.21.2.77

Castro, S. L., Scandura, T. A., \& Williams, E. A. (2004). Validity of Scandura and Ragins' (1993) multidimensional mentoring measure: An evaluation and refinement. Paper presented at the Southern Management Association Meeting, San Antonio, TX.

Cohen, J. (1992). A power primer. Quantitative Methods in Psychology, 112, 155-159.

Costanza, D. P., Badger, J. M., Fraser, R. L., Severt, J. B., \& Gade, P. A. (2012). Generational differences in work-related attitudes: A meta-analysis. Journal of Business and Psychology, 27, 375-394. doi:10.1007/s10869-012-9259-4

Dawley, D. D., Andrews, M. C., \& Bucklew, N. S. (2007). Mentoring, supervisor support, and perceived organizational support: What matters most? Leadership \& Organization Development Journal, 29, 235-247. doi:10.1108/01437730810861290

Dawley, D. D., Andrews, M. C., \& Bucklew, N. S. (2010). Enhancing the ties that bind: Mentoring as a moderator. Career Development International, 15, 259-278. doi:10.1108/13620431011053730

Dickerson, F. B., Savage, C. G., Schweinfurth, L. B., Medoff, D. R., Goldberg, R. W., Bennett, M., \& DiClemente, C. (2016). The use of peer mentors to enhance a smoking cessation intervention for persons with serious mental illnesses. Psychiatric Rehabilitation Journal, 39, 5-13. doi:10.1037/prj0000161

Dreher, G. F., \& Ash, R. A. (1990). A comparative study of mentoring among men and women in managerial, professional, and technical positions. Journal of Applied Psychology, 75, 539-546.

Eisenberger, R., Armeli, S., Rexwinkel, B., Lynch, P. D., \& Rhoades, L. (2001). Reciprocation of perceived organizational support. Journal of Applied Psychology, 86, 42-51. doi:10.1037//00219010.86.1.42

Eisenberger, R., Huntington, R., Hutchison, S., \& Sowa, D. (1986). Perceived organizational support. Journal of Applied Psychology, 71, 500-507.

Fritz, M. S., \& MacKinnon, D. P. (2007). Required sample size to detect the mediated effect. Association for Psychological Science, 18, 233-239.

Goldberg, L. R. (1990). An alternative "description of personality": The big-five factor structure. Journal of Personality and Research, 59, 1216-1229. doi:10.1037/0022-3514.59.6.1216

Grant, A. M. (2008). Designing jobs to do good: Dimensions and psychological consequences of prosocial job. The Journal of Positive Psychology, 3, 19-39. doi:10.1080/17439760701751012

Horvath, M., Wasko, L. E., \& Bradley, J. L. (2008). The effect of formal mentoring program on organizational attraction. Human Resource Development Quarterly, 19, 323-349. doi:10.1002/hrdq. 1244

Kashiwagi, D. T., Varkey, P., Cook, D. A. (2013). Mentoring programs for physicians in academic medicine: A systematic review. Academic Medicine, 88, 1029-1037. doi:10.1097/ACM.0b013e318294f368

Kram, K. E. (1985). Mentoring at work. Glenview, IL: Scott, Foresman.

Kurteiss, J. N., Eisenberger, R., Ford, M. T., Buffardi, L. C., Stewart, K. A., \& Adis, C. S. (Published online March 2015). Perceived organizational support: A meta-analytic evaluation of organizational support theory. Journal of Management, 1-31. doi:10.1177/0149206315575554

Lohrke, F. T., Holloway, B. B., \& Woolley, T. W. (2010). Conjoint analysis in entrepreneurship research: A review and research agenda. Organizational Research Methods, 13, 16-30. doi:10.1177/1094428109341992

Lyons, S. T., Ng, E.S., \& Schweitzer, L. (2014). Changing demographics and the shifting nature of careers: Implications for research and human resource development. Human Resource and Development Review, 13, 181-206. doi:10.1177/1534484314524201

Matarazzo, K. L., \& Finkelstein, L. M. (2015). Formal mentorships: Examining objective-setting, event participation and experience. Journal of Managerial Psychology, 30, 675-691. doi:10.1108/JMP02-2012-0041 
Newby, T. J., \& Heide, A. (2013). The value of mentoring. Performance Improvement Quarterly, 26, 141-158. doi:10.1002/piq.21149

Parise, M. R., \& Forret, M. L. (2008). Formal mentoring programs: The relationship of program design and support to mentors' perceptions of benefits and costs. Journal of Vocational Behavior, 72, 225-240. doi:10.1016/j.jvb.2007.10.011

Ragins, B. R., \& Cotton, J. L. (1993). Gender and willingness to mentor in organizations. Journal of Management, 19, 97-111. doi:10.1177/014920639301900107

Ragins, B. R., \& Kram, K. E. (Eds.). (2007). The handbook of mentoring at work: Theory, research, and practice. Thousand Oaks, CA: Sage.

Ragins, B. R., \& Scandura, T. A. (1999). Burden or blessing? Expected costs and benefits of being a mentor. Journal of Organizational Behavior, 20, 493-509. doi:10.1002/(SICI)10991379(199907)20:4<493::AID-JOB894>3.0.CO;2-T

Reid, E., \& Ramarajan, L. (2016). Managing the high intensity workplace. Harvard Business Review, 94, 84-90.

Rhoades, L., \& Eisenberger, R. (2002). Perceived organizational support: A review of the literature. Journal of Applied Psychology, 87, 698-714. doi:10.1037//0021-9010.87.4.698

Saucier, G. (1994). Mini-markers: A brief version of Goldberg's unipolar big-five markers. Journal of Personality Assessment, 63, 506-516.

Shanock, L. R., \& Eisenberger, R. (2006). When supervisors feel supported: Relationships with subordinates' perceived supervisor support, perceived organizational support, and performance. Journal of Applied Psychology, 91, 689-695. doi:10.1037/0021-9010.91.3.689

Shapiro, D. N., Chandler, J., \& Mueller, P. A. (2013). Using Mechanical Turk to study clinical populations. Clinical Psychological Science, 1, 213-220. doi:10.1177/2167702612469015

Stenfors-Hayes, T., Kalén, S., Hult, H., Dahlgren, L. O., Hindbeck, H., \& Ponzer, S. (2010). Being a mentor for undergraduate medical students enhances personal and professional development. Medical Teacher, 32, 148-153. doi:10.3109/01421590903196995 









